\title{
WACANA PRANAWA MANTRA “OM" DALAM PERSPEKTIF LINGUSTIK BUDAYA
}

\author{
I Wayan Gara \\ STKIP Agama Hindu Singaraja, Singaraja, Indonesia \\ iwayangara123@gmail.com
}

\begin{abstract}
ABSTRAK
Mantra dalam agama Hindu merupakan salah satu instrumen yang sangat vital peranannya untuk pemujaan (sembahyang), persembahan yadnya, meditasi, dan sebagainya. Demikian pula mantra/japa mantra memiliki daya magis dan mistik untuk keselamatan, kejayaan, dan kesuksesan dalam meraih cita-cita. Ketepatan dalam perapalan suatu mantra/japa mantra sesuai dengan fungsinya dapat memberikan fibrasi daya-daya mantra/japa mantra dimaksud.

Pranawa Mantra "Om" sangat menarik perhatian untuk diangkat dalam sebuah penelitian ilmiah. Studi terhadap sebuah realitas simbolik yang fenomenal ini mengkaji bentuk, makna, dan fungsi Pranawa Mantra "Om". Tujuannya untuk mengungkapkan realitas hubungan bahasa dan budaya dalam Pranawa Mantra "Om" yang memiliki bentuk, makna, dan fungsi tertentu. Hasil penelitian ini bermanfaat untuk menambah wawasan ilmu pengetahuan, terutama bidang ilmu interdispliner bahasa dan budaya. Demikian pula hasil penelitian ini berguna sebagai salah satu referensi sehubungan dengan studi linguistik budaya dan spiritual yang bernuansa Hindu.

Studi Pranawa Mantra "Om" menggunakan teori linguistik budaya, yakni pengkajian bahasa dalam konteks budaya, terutama mempelajari makna di balik simbol budaya yang fungsional. Metodologi penelitiannya meliputi: (1) pendekatan fenomenologik yang religius, empirik, komprehensif, dan etnografik - etnometodologik; (2) metode pengumpulan data dilakukan dengan mengadakan observasi, wawancara, dan studi pustaka, yang ditunjang dengan teknik catat, pancing, dan rekam; (3) metode analisis data mencakup: reduksi data, penyajian data, dan simpulan.
\end{abstract}

Kata kunci: bentuk, fungsi, makna, spiritual, agama Hindu, Pranawa Mantra "Om", dan Linguistik Budaya.

\section{PENDAHULUAN}

Mantra dalam agama Hindu merupakan salah satu instrumen yang sangat vital peranannya untuk pemujaan (sembahyang), persembahan yadnya, meditasi, dan sebagainya. Umat Hindu sangat yakin bahwa mantra mengandung daya penyucian untuk ketenangan, kedamaian, dan pencerahan jiwa (spiritual). Demikian pula mantra/japa mantra memiliki daya magis dan mistik untuk keselamatan, kejayaan, dan kesuksesan dalam meraih cita-cita. Ketepatan dalam perapalan suatu mantra/japa mantra sesuai dengan fungsinya dapat memberikan fibrasi daya-daya mantra/japa mantra dimaksud. 
Linguistik Budaya mempertimbangkan hubungan timbal balik antara bahasa dan pikiran (budaya). Bahasa dan budaya dapat saling mempengaruhi atau menentukan satu sama lain. Hipotesis Sapir - Whorf (dalam Carrol, 1956) pada intinya menyatakan bahwa bahasa berproses mempengaruhi pikiran yang bermuara pada perilaku dan tindakan sebagai produknya. Misalnya, tanda larangan "Dilarang Merokok" pada areal dekat pompa premium. Hal tersebut merupakan bahasa yang dapat mempengaruhi pikiran orang yang perhatian pada larangan tersebut sehingga ia tidak akan merokok di sekitar tempat itu. Akan tetapi, orang yang berpikiran ceroboh ("kurang berbudaya") bisa saja mengabaikan tanda larangan seperti itu, yang tentunya berisiko dapat terjadi kebakaran. Itulah relativitas bahasa. Dalam kaitan itu, linguistik budaya cenderung memandang dan mengkaji hubungan bahasa dan budaya yang positif dengan mengabaikan yang "kurang berbudaya". Studi bahasa dalam perspektif linguistik budaya meliputi dimensi hubungan bahasa dan budaya, antara lain: bahasa sebagai bagian, indeks, dan simbol budaya (band. Whorf, 1979:207219; Wardhaugh, 1986:212-213; Wierzbicka, 1992:1; Fishman dalam Kuper dan Kuper, 1996:547-548).

Konsep Linguistik Budaya tidak terlepas dari strukturalisme, ajaran Saussure (1916) yang dalam perkembangannya melahirkan semiotik (semiologi), yaitu studi tentang tanda. Bahasa merupakan sistem tanda yang utama, yang terdiri atas bentuk (signifiant) dan makna (signifie). Zoest (1993: 1-7) menyebutkan bahwa semiotik adalah cabang ilmu yang berhubungan dengan tanda, seperti sistem tanda dan proses penggunaannya. Bahasa dan kebudayaan dapat dipahami melalui sistem tanda. Hubungan timbal balik bahasa dan kebudayaan, bahasa dalam kebudayaan, atau bahasa menandai kebudayaan dapat dipandang sebagai suatu perangkat sistem tanda. Geertz memandang kebudayaan sebagai "teks", yang unsur-unsurnya dapat dikaji maknanya. la bahkan memandang kebudayaan sebagai sistem semiotik. Studi (Linguistik) Kebudayaan berarti mempelajari kode-kode bersama maknanya (Keesing, 1981:48-49).

Bahasa sebagai realitas teks linguistik sistemik fungsional mencakup bahasa sebagai realitas fisik, sosial, dan semiotik. Dalam kaitan itu, makrofungsi (ideasional, interpersonal, dan tekstual) merupakan metafungsi yang dianggap sebagai mekanisme yang mengubah makna menjadi sistem gramatikal; struktur gramatikal dan tindak ujar. (Halliday dan Hasan, 1989: 15-28). Sebelumnya, Pike (1967) menggunakan istilah etik dan emik terhadap hubungan metafungsi yang bersifat umum dan khusus. Penentuan kebermaknaan terhadap realitas kebahasaan tersebut selalu terkait dengan ketiga metafungsi itu. Konsep etik emik mengacu pada pemahaman (makna) simbol budaya. Etik adalah persepsi mayarakat pemilik budaya yang bersangkutan, sedangkan emik adalah persepsi pemikir, peneliti, atau penginterpretasi makna simbol budaya. Penafsiran makna tanda (budaya) bertitik tolak dari makna primernya. Masyarakat pendukung budaya memberikan makna metabahasa atau konotasi. Kajian makna metabahasa yang bertumpu pada makna primer sebuah tanda disebut hermeneutik. Hal tersebut merupakan model cara berpikir filosofis untuk mengungkapkan makna di balik simbol, pengalaman hidup sehari-hari, sejarah, seni, religi, dan berbagai fenomena hidup lainnya (Poedjosoedarmo, 2001: 87168; Hoed, 1994: 8-26; Palmer, 1969: 3; Sumaryono, 1999: 8-24). Jadi, linguistik sistemik fungsional memberikan tekanan pada makna berdasarkan fungsi bahasa dalam masyarakat. Makna dapat dilihat dari segi relasi dan akibatnya dalam sistem. Demikianlah fungsionalisme yang memberikan tekanan 
pada relasi dan fungsi (band. Bell, 1974; Hoed, 1994: 10; Ibrahim, 1995: 132_ 137).

Seiring dengan perkembangan dan tantangan zaman yang semakin kompleks, umat Hindu perlu bercermin pada ajaran "Catur Yuga". Misalnya, perkembangan iptek dan informatika pada zaman modern yang mengglobal dewasa ini, yang di Hindu ditengarai sebagai zaman Kali Yuga. Kiat untuk dapat menghadapi zaman Kali Yuga yang tipikal tersebut, antara lain perlu disikapi dengan melakukan japa (Pranawa Mantra "Om"), namasmaranam, dana punia; tapa, yoga, brata, dan semadi. Itu semua dimaksudkan untuk dapat mengantisipasi, menghindari, dan menjauhkan diri dari pengaruh buruk perkembangan zaman Kali Yuga.

Bahasa merupakan sistem lambang bunyi yang arbiterer dan konvensional, yang dapat dipelajari dan disepakati oleh suatu anggota masyarakat untuk dipakai sebagai sarana berkomunikasi, baik secara verbal maupun non verbal. Pranawa Mantra "Om" adalah bahasa, yang oleh umat Hindu sangat diyakini sebagai Nada (Suara, Bunyi, atau Sabda) Brahman, Tuhan yang Mahaesa (band. Jendra, 1980: ).

Pranawa Mantra "Om" dalam realisasinya yang simbolik sebagai Wijaksara (Om/Ong-kara) tergolong sebagai aksara suci dan fungsional sehubungan dengan praktek keagamaan umat Hindu (band. Bagus, 1980: ). Studi Pranawa Mantra "Om" dan realisasinya yang simbolik dimaksud sangat penting bagi umat Hindu, terlebih-lebih bagi peminat dan penekun spiritual.

Nada Brahman merupakan sebuah realitas bahasa, yaitu referensi dari simbol Pranawa Mantra "Om", yang terdiri atas sebuah kata bersuku satu. Umat Hindu Bali mengucapkan atau merapalkan Pranawa Mantra "Om" secara bervariasi dengan tulisan fonetis: \{öm, ön, wön, aüm, üm\}. Tiga buah variasi bunyi bahasa yang pertama itu terjadi atas dasar penyesuaian bunyi vokal atau suara sandi \{aú\} menjadi $\{0 ̈ / w o ̈\}$, berkonsonan nasal atau maulu candra $\{\mathrm{m} / \mathrm{h}\}$; sedangkan dua buah variasi bunyi bahasa yang terakhir terjadi atas dasar penyesuaian deretan bunyi vokal \{aü\} dan penyingkatan/penghilangan sebuah bunyi vokal dalam \{aü\} menjadi \{ü\}, berkonsonan nasal atau maulu candra $\{\mathrm{m} / \mathrm{n}\}$ tanpa perubahan status bunyi bahasa.

Filsafat Nada Brahman "Om" dalam perpektif Upanisad sangat dipercaya oleh orang-orang suci dan penganutnya bahwa Brahman menciptakan dunia dengan segala isinya ditandai dengan Sabda Brahman "Om". Penciptaan dunia dimaksud diikuti dengan siklus pemeliharaan (kehidupan) dan penyerapan, pemusnahan, atau kematian yang berkesinambungan sepanjang zaman. Demikianlah, akhirnya kita dapat melihat kenyataan kini bahwa Pranawa Mantra "Om" menempati posisi utama dan strategis dalam setiap mantra suci Hindu, baik yang terdapat pada Weda maupun mantra-mantra fungsional yang ditengarai bersumber pada Weda, antara lain: Mantra Ganapati, Mantra Siwa Panca Aksari, Narayana Astaksari, Mantra Gayatri; mantra-mantra dalam lontar/buku Kusuma Dewa, Kajang Recadana, usada, pakakas, tumbal, dan sebagainya. (lih. Chwdhri, 2003: 119-151; Anandakusuma, 1973: 12-37). Pemahaman umat atau bakta terhadap aspek suara, makna, dan aplikasinya yang benar dapat mengantarkannya pada pencerahan spiritual. Hal tersebut dapat diperoleh terutama di bawah bimbingan guru spiritual sejati (Band. Suamba, 2004: 77-81; Anandas Ra, 2008: 61-117; Darmayasa, 2007: 52-55).

Penulis bukanlah guru spiritual, akan tetapi seorang manusia biasa yang merasa tertarik pada sebuah objek studi yang fenomenal itu. Namun demikian, pengkajian Pranawa Mantra "Om" dalam perspektif linguistik budaya yang 
meliputi bentuk, makna, dan fungsi tidak dipungkiri bernuansa spiritual. Studi ini diharapkan dapat mengungkapkan dan memberikan gambaran sekilas tentang aspek bahasa dalam Pranawa Mantra "Om" yang menyiratkan budaya umat Hindu yang spesifik dan universal.

\section{METODE}

Penelitian Pendahuluan ini bersifat kualitatif, yang pelaksanaannya berlangsung di Bali. Dalam kaitan itu, dipertimbangkan kesesuaian penggunaan pendekatan, metode, dan teknik penelitian. Studi ini menggunakan pendekatan fenomenalogik yang religius, empirik, komprehensif, dan etnografik etnometodologik. Artinya, Pranawa mantra "Om" sebagai sebuah gejala linguistik budaya yang bernuansa religius, magis, dan mistik sudah ada dan berlangsung secara wajar sesuai dengan fungsinya dalam tradisi, acara, upakara/upacara agama Hindu. Peneliti tidak melakukan eksperimen lagi untuk memperoleh data penelitian. Lebih-lebih peneliti sebagai umat Hindu yang lahir dan dibesarkan di Bali sehingga dengan mudah dapat terjun dan berbaur serta terlibat dalam berbagai kegiatan seminar, pasantian, pasraman, masima krama, adat, dan agama Hindu dengan masyarakat sesama umat Hindu Bali dalam rangka pemerolehan data penelitian yang seluas-luasnya. Metode penelitiannya meliputi: observasi terlibat, wawancara, dan studi pustaka yang disertai dengan teknik catat, pancing, dan rekam. Analisis data dilakukan dengan metode yang mencakup: reduksi data, penyajian data, dan simpulan (lih. Muhadjir, 1989: 155-174; Miles dan Huberman, 1992: 15-21; Moleong, 2002: 2-15; band. Gara, 2006: 86-89).

Studi ini bertumpu pada teori Linguistik Budaya. Bagus (1996) menggagas dan sangat menaruh perhatian terhadap "Linguistik Kebudayaan", yang dalam kuliah-kuliahnya di Pascasarjana Linguistik, Fakultas Sastra, Universitas Udayana selalu menekankan pentingnya segera diwujudkan, diterapkan, dan dikembangkan bidang ilmu interdisipliner bahasa dan budaya.

Bunyi vokal $\{0 ̈\}$ memiliki alofon atau variasi vokal yang terdiri atas: $\{0$, ò, ö\} (Band. Jendra dalam Bagus [Ed.], 1975: 51-75; Jendra, 1980: 16; Anom, dkk., 1983: 7). Hal tersebut menjadi lebih jelas dengan menghadirkan peta bunyi vokal bahasa Bali berikut ini. 
Depan Atas/Tinggi Belakang

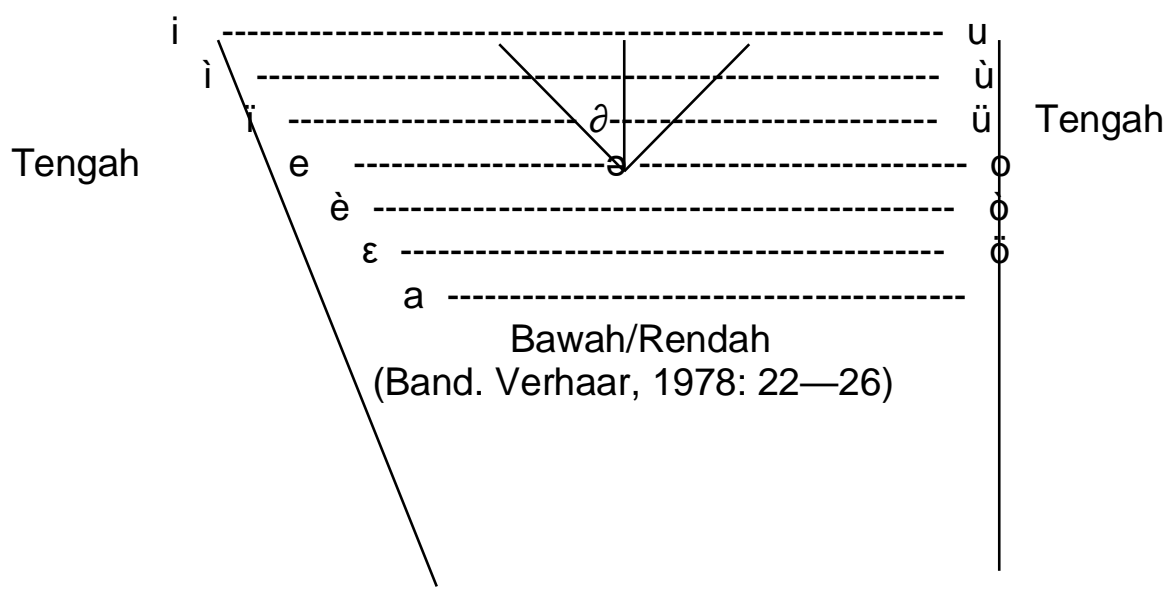

Realisasi bunyi-bunyi vokal seperti yang tampak pada peta di atas dapat berkorespondensi tanpa mengubah arti. Misalnya: \{mèön\} - \{mïö\}\} 'kucing', \{dòri\} - \{dùri\} 'belakang', \{sato\} - \{satə\} 'binatang, hewan', \{lüngüh\}- \{lïngïh\}'tempat duduk, status sosial', \{dùrüng\} - \{dèreng $\}$ 'belum', \{ilu $\}$ - \{malu\} 'dulu, lama', \{margə $\}-\{$ margi $\}$ 'jalan', $\{j \partial l e\}-\{j \partial l ə\}$ 'jelek, buruk', \{pдdə\} - \{padə\} 'sama', dan sebagainya.

Sebuah bunyi vokal pada suatu deretan bunyi bermakna dapat berada pada posisi depan, tengah, dan akhir; ada yang bersuku terbuka dan bersuku tertutup. Misalnya, \{mè ön\} dan \{mì - ön\} yang sama-sama berarti 'kucing'. Bunyi vokal \{ö\} pada kedua bentuk deretan bunyi \{ön\} di depan tergolong bersuku tertutup. Hal tersebut mirip dengan Pranawa Mantra "Om", yakni bunyi vokal \{ö\}pada bentuk deretan bunyi bermakna atau kata bersuku satu tertutup \{öm\} 'Nada Brahman (Tuhan)'.

Penyesuaian bunyi dapat juga terjadi sehubungan dengan pertemuan bunyi dalam suatu suku kata atau kata. Misalnya: $\{$ sa- $\}+\{$ ümah $\}$ 'rumah' $\rightarrow$ \{sòmah $\}$ 'suami, istri', \{batu $\}$ 'batu' $+\{-$ an $\} \rightarrow$ \{batön\} 'batu pemberat pancing'. Realitas bunyi bahasa seperti ini disebut samdhi, sandi, atau sutra. Tampaknya gejala persandian yang mirip dengan dua contoh bentuk deretan bunyi bermakna di depan juga terjadi pada Pranawa Mantra "Om". Hal itu dapat dirujuk filsafat atau asal-usulnya dalam perspektif Upanisad bahwa Pranawa Mantra "Om" adalah Sabda Tuhan yang dalam manifestasiNya yang simbolik terdiri atas tiga buah bunyi (aksara) suci yang diucapkan dengan suara panjang dan bergema, yaitu "A - U - M". Deretan tiga buah bunyi (aksara) tersebut secara fonetis dapat diidentifikasikan atau tandai dengan \{aüm\} 'manifestasi Tuhan sebagai pencipta (Brahma), pemelihara (Wisnu), dan pemusnah (Siwa)'.

Persandian bunyi \{aüm\} menjadi \{öm\} diyakini mempunyai vibrasi yang luar biasa sehingga menjadi pusat perhatian bagi umat Hindu, lebih-lebih bagi peminat, bhakta, atau penekun spiritual, yang apabila dalam pengucapannya dilakukan dengan benar di bawah bimbingan guru spiritual sejati maka tidak dipungkiri hasilnya adalah pencerahan jiwa yang tenang, damai, dan bahagia. Dalam kaitan itu, banyak cara pengucapannya yang dilakukan oleh orang-orang suci untuk memperoleh hasil dimaksud. Dalam Mantra Sastra dinyatakan bahwa Pranawa Mantra "Om" dapat diucapkan dalam 170 cara. Demikian pula Madame 
Blawatsky mengutip dari beberapa karya India kuno bahwa Pranawa Mantra "Om" dapat diucapkan dalam 250 intonasi yang berbeda-beda dan tahap siddhi dapat dicapai dengan tiaptiap metode yang berbeda-beda. Kemujaraban suara berpengaruh pada emosi. Bunyi (aksara): A-kara dapat membunuh krodha, U-kara dapat membunuh dwesa, dan M-kara dapat membunuh rasa takut. Jadi, Pranawa Mantra "Om" yang simbolik dapat membunuh ego dalam diri manusia (band. Wiwekananda, 2008: 34--37; Suamba, 2004: 63-68).

Anand Krisna (2007:48-67) dalam tulisannya yang berjudul "Pancaksara, Membangkitkan Keagamaan dalam Diri Manusia" menyebutkan bahwa suara awal penciptaan adalah "A" (mulut terbuka) yang dibaca seperti "e" dalam kata "apel". Itulah Brahman. Selanjutnya adalah suara kehidupan "U" (mulut terbuka sedikit dan membundar) yang dipersonifikasikan sebagai Wisnu. Setelah itu, suara peleburan " $M$ " yang mendengung dengan mulut tertutup merupakan manifestasi Tuhan sebagai Maheswara. Melalui pengalamannya yang menggeluti bidang spiritual ditegaskan bahwa "AUM" adalah namaNya. Itulah suara dasar. Tuhan adalah sumber energi. Adapun energi dalam frekuensi rendah adalah suara. Apabila kita ingin berhubungan dengan Tuhan maka panggillah namaNya dengan memanfaatkan energi, baik energi yang terkandung di dalam diri maupun energi alam semesta. Sebuah ilustrasi yang dikemukan berikut ini sangat menarik untuk direnungkan. Dalam keheningan di rumah, cobalah membuka pintu kamar sedikit saja. Bersama hembusan angin kita akan mendengar Suara Awal, Sabda Alam. Barangkali "AUM" terdengar seperti "ALM", atau seperti apa. Yang jelas suara alam itu terdengar. Jika kita meyakininya maka "AUM", "ALM", atau yang lainnya, terserah menurut pendengaran kita masing-masing. Itulah Brahman. Sesungguhnya Hyang Terdengar itu satu dan sama adanya.

Berikut ini dikemukakan beberapa buah mantra untuk persembahyangan (muspa panca sembah) dan japa mantra yang menunjukkan posisi Pranawa Mantra "Om" yang strategis dan utama (lih. Winara, tt.:3-32; Anandakusuma, 1973: 34-36; Chawdhri, 2003: 115-151).

(1) Mantra Muspa/Sembah (Panca Sembah)

a. Mantra Sembah Bhakti Tanpa Bunga

Om Atma Tatwa Atma Shuddhaya Mam Swaha.

Artinya:

Tuhan, Atma dari Atma Tatwa, semoga hamba disucikan.

b. Mantra Sembah Bhakti dengan Bunga Putih

(a) Om Adityasya Paramjyotih, Rakta Tejo Namo Stute, Shweta Pangkaja Madhyasthe, Bhaskaraya Namo Stute.

(b) Om Pranamya Bhaskara Dewam, Sarwa Klesha Winashanam, Pranamya Aditya Shiwartham, Bhukti Mukti Warapradam.

(c) Om Hram Hrim Sah Parama Shiwa Adityaya Namah Swaha.

Artinya:

(a) Tuhan, Aditya dalam perwujudan cahaya merah cemerlang berkilauan, putih cuci, bersemayam di tengah-tengah laksana teratai, dan sumber cahaya yang Mulia.

(b) Tuhan, Dewa Bhaskara yang merupakan cahaya sumber segala sinar, semoga sirna segala dosa dan kotoran yang ada dalam jiwa karena yang Mulia adalah sumber kebahagiaan lahir - batin.

(c) Tuhan, Parama Shiwa Aditya yang Mulia, yang memberi keselamatan. 
c. Mantra Muspa dengan Bunga Berwarna Merah

Om Namah Dewah Adhisthanaya, Sarwa Wyapine Shiwaya, Padmasana Eka Pratisthaya, Ardhanareshwaraya Namo Namah Swaha.

Artinya:

Tuhan, hamba memujaMu sebagai penguasa sumber sinar yang bersingasana paling utama, sebagai Shiwa penguasa semua makhluk, sebagai satu-satunya penegak segala yang bersemayam di Padmasana.

d. Mantra Sembah Bhakti dengan Bunga Berwarna Hijau (Kawangen)

(a) Om Anugrahah manoharam, Dewadatta Nugrahakam, Hyarcanam Sarwa Pujanam, Namah Sarwa Nugrahakam.

(b) Om Dewa Dewi Maha Siddhi, Yajnaka Ta Mulat Idam, Laksmi Siddhishca Dirghayuh, Nirwighna Sukha Wrddhitah.

Artinya:

(a) Tuhan, Dewa Datta yang Mulia, semoga melimpahkan segala anugrah yang mengembirakan dan kebahagiaan yang cicita-citakan.

(b) Tuhan, Dewa-Dewi sumber segala pengetahuan, berasal dari korban suci, semoga melimpahkan kemakmuran, pengetahuan, umur panjang, keselamatan, dan kebahagiaan.

e. Mantra Muspa Tanpa Bunga

(a) Om Dewa Suksma Parama Acintyaya Namah Swaha.

(b) Om Shantih, Shantih, Shantih, Om.

Artinya:

(a) Tuhan, Dewa Suksma Parama Acintya yang Mulia.

(b) Tuhan, (semoga) damai, damai, damai, (ya) Tuhan.

(2) Japa Mantra

a. Mantra Ganapati

Om Gam Ganapataye Namah.

Artinya:

Tuhan, Ganapati yang Mulia, semoga menghalau segala rintangan dan halangan.

b. Mantra Shiwa Panca Aksari

Om Namah Shiwaya.

Artinya:

Tuhan, Shiwa yang Mulia.

c. Mantra Narayana Asta Aksari

Om Namah Narayanaya.

Artinya:

Tuhan, Narayana yang Mulia.

d. Mantra Saraswati

Om Aim Kalim Saum Saraswatyai Namah.

Artinya:

Tuhan, Saraswati yang Mulia, semoga memberikan kemahiran berbicara.

e. Mantra Gayatri

Om Bhur Bhuwah Swah, Tat Sawitur Warenyam, Bhargo Dewasya Dhimahi, Dhiyo Yo Nah Pracodayat.

Artinya: 
Tuhan yang Maha Kuasa atas dunia bawah (bumi), dunia tengah (udara), dan dunia atas (langit); semoga melimpahkan kekuatan pada pikiran, penerangan cahaya yang Maha Suci.

f. Mantra Mahamrtyunjaya

Om Trayambakam Yajamahi, Sugandhim Pushtivardhanam, Oovaa Rukamiva Bandhanat, Mrtyor mushee Yamaamrutat, Om Hreem Namaah Shivaaya, Aum Shanti Shanti Shanti.

Artinya:

Tuhan, segala puja dan hormat kepada (Shiwa) yang bermata tiga, yang harum semerbak dan memelihara semua makhluk. Semoga membebaskan (saya) dari lingkaran kelahiran dan kematian serta tercapainya keabadian. Seperti halnya buah mentimun yang memutuskan ikatan (ketika buah tersebut telah matang seluruhnya). Tuhan, (semoga) damai, damai, damai (Paramita, 2010: 1).

Posisi strategis dan utama Pranawa Mantra "Om" dalam mantra-mantra di depan pada intinya menunjukkan pengutamaan dalam memuja Tuhan dengan berbagai manifestasiNya yang Mulia, Suci, Maha Kuasa, dan sebagainya. Adapun manifestasi Tuhan yang tersirat dalam mantra/japa mantra di depan, antara lain: Atma dari Atma Tatwa, Aditya, Dewa Bhaskara, Parama Shiwa Aditya, Shiwa, Dewa Datta, Dewa-Dewi, Dewa Suksma Parama Acintya, Ganapati, Narayana, dan Saraswati. Umat Hindu atau bhakta memujaNya untuk mencapai tujuan tertentu, seperti tersirat dalam setiap mantra/japa mantra tersebut, antara lain: kesucian, kecemerlangan; terhapusnya segala dosa dan kotoran pada jiwa, terhindar dari segala rintangan dan halangan, kemakmuran, kebahagiaan, kemahiran berbicara, kebebasan, dan kedamaian.

Beberapa mantra di depan tampak juga menggunakan samput yang ditempatkan pada awal baris sebuah mantra, seperti: (1) Mantra Sembah Bhakti (Panca Sembah Urutan ke-2, baris [c], Hram Hrim Sah 'semoga memperoleh penerangan suci untuk pencerahan jiwa'), (2) Mantra Ganapati (Srim Hrim Kalim Glaum [Gam] 'semoga terhindar dari segala rintangan dan halangan'), (3) Mantra Saraswati (Aim Kalim Saum 'semoga mahir berbicara'), dan (4) Mantra Mahamrtyunjaya (Hrim 'semoga membebaskan dari lingkaran kelahiran dan kematian serta tercapainya keabadian'). Samput adalah kata-kata khusus yang memiliki kekuatan yang amat besar dalam sebuah mantra saktiljapa mantra. Penggunaan samput harus dipertimbangkan dengan sangat hati-hati. Adapun samput bisa digunakan pada awal, tengah, atau akhir sebuah mantra.

Japa Mantra, yang di dalamnya termasuk yang ber-samput merupakan mantra dasar. Japa Mantra dimaksud harus digunakan secara berulang-ulang. Penggunaannya dalam Japa dan Upasana untuk menuntun pada tahap mencapai semadhi dan siddhi.

Sebelum melakukan pemujaan terhadap Tuhan dengan berbagai manifestasiNya, umat Hindu, bhakta, sadhaka, pinandita, atau pandita melakukan penyucian diri yang disertai dengan beragam mantra ber-Pranawa Mantra "Om". Penyucian diri dimaksud dilakukan mulai dari tindakan baru bangun, mandi, berbusana, asana, pranayama, puspadanta, dan sebagainya (lih. Anandakusuma, 1973:11—40; Winara, tt.: 1—42; Chawdhri, 2003: 97-189).

\section{MAKNA DAN FUNGSI}

Bentuk lingual Pranawa Mantra "OM" dengan suara dasar "A - U - M" seperti yang telah dikemukakan di depan memiliki makna inti, yaitu 'Sabda, Suara, atau Nada Brahman'. Itulah Brahman/Tuhan yang Mahaesa. Bunyi (aksara) "Om" telah diyakini kebermaknaannya oleh 
orang-orang suci, bhakta, dan umat Hindu pada masa lalu hingga kini seiring dengan perkembangan rasa religusitasnya. Oleh karena keutamaan dan perananNya yang strategis memenuhi segalanya sesuai dengan hakikat kemahaesaanNya maka keberadaanNya menjadi pusat perhatian dan fungsional. Begitu megah, cemerlang, halus, luas, dan kompleksnya Sabda Brahma itu, sepertinya akan sulit dan tidak habis-habisnya untuk dapat mengungkap dengan tuntas realitas yang fenomenal itu. Studi ini baru hanya secuil usaha dalam mengungkapkan yang hakiki tersebut. Dalam perspektif linguistik budaya, "Om" memiliki makna dan fungsi budaya yang dapat diidentifikasikan dan diklasifikasikan, antara lain: (1) kemahaesaan dan kemanunggalan Tuhan, (2) siklus/daur kehidupan, (3) rasa keagamaan, moral, dan spiritual; (4) ritus, (5) daya mistik dan magis, (6) penginderaan relatif, dan (7) keseimbangan.

Kemahaesaan dan Kemanunggalan Tuhan

Pranawa Mantra "Om" menyiratkan makna kemahaesaan dan kemanunggalan Tuhan. Pranawa Mantra yang suci ini merupakan Suara Brahman yang meliputi ruang dan waktu sekaligus meresap ke seluruh alam semesta beserta isinya. Artinya, Tuhan berada di luar dan di dalam ciptaanNya (bhur, bhwah, dan swah) sebelum dan sesudah masa lalu, masa sekarang, dan masa yang akan datang. Manifestasi Tuhan sebagai Brahma (Pencipta), Wisnu (Pemelihara), dan Siwa (Pelebur) memenuhi ruang dan waktu, termasuk di dalamnya umat manusia yang terbangun atas Tri Guna (satwam, rajas, dan tamas) meresap dan manunggal ke dalam "Om". Demikian pula "Om" berada di luar manifestasiNya itu. Hal tersebut tercermin dalam Mantra Gayatri. Realitas keberadaannya juga dipertegas dalam Mandukya Upanisad, ayat 1 sebagai berikut. "Semua yang ada di dunia ini adalah Om, dan ini adalah eksposisi Om. Masa lalu, sekarang dan yang akan datang, semuanya adalah Om. Demikian juga apa saja yang ada di luar ikatan waktu adalah juga Om" (Suamba, 2004: 3-6).

Sehubungan dengan realitas makna tersebut di atas, Pranawa Mantra "Om" berfungsi sebagai media untuk menghubungkan diri kepada Tuhan dengan segala manifestasiNya. Pengucapan yang dilakukan berulang-ulang atau dengan ber-japa secara teratur, bersungguhsunguh, serta mantap diyakini akan dapat mencapai tahapan pencerahan tertentu dari Brahman.

\section{Siklus/Daur kehidupan}

Pembicaraan topik ini masih berkaitan dengan pembahasan makna kemahaesaan dan kemanunggalan Tuhan dan fungsinya itu. Kesinambungan fungsi utpathi (penciptaan) oleh Brahma, stithi (pemeliharaan) oleh Wisnu, dan pralina (peleburan) oleh Siwa di Buana Agung dan Buana Alit merupakan realita kemahaesaan dan kemanunggalan Tuhan dalam mengatur siklus ciptaanNya. Manifestasi Sabda Brahman tersebut berlangsung terus-menerus sepanjang zaman.

Yadnya ditengarai menjadi landasan sehubungan kesinambungan siklus utpethi, stithi, dan pralina melalui fungsi manifestasi Tuhan sebagai Brahma, Wisnu, dan Siwa. Oleh karena itu maka umat manusia yang dianugrahi Tri Premana (bayu, sabda, dan idep) berkewajiban untuk melaksanakan yadnya agar terjadi keseimbangan dan keberlangsungan siklus utpethi, stithi, dan pralina di Buana Agung dan Buana Alit. Dalam kaitan itu, Pranawa Mantra "Om" berfungsi sebagai dasar untuk introspeksi diri dan melakukan refleksi terhadap swadharma melaksanakan yadnya sesuai dengan kemanpuan serta tingkatan menurut desa, kala, dan patra. 
Rasa Keagamaan, Moral, dan Spiritual

Sabda Brahman "Om" yang simbolik mencerminkan rasa keagamaan penganutnya. Hal ini identik dengan semboyan kesetiaan dan kebanggaan terhadap bahasa lbu, "Bahasa Menunjukkan Bangsa". Bunyi (aksara) "Om" adalah lambang identitas, kebanggaan, kesetiaan, dan sarana untuk menghubungkan diri, baik kepada sesama umat sedharma maupun Tuhan yang Mahaesa. Sikap mendukung terhadap hak milik, rasa keagamaan, kebudayaan, dan sebagainya merupan kewajiban moral menuju ke pencerahan jiwa.

Bunyi (aksara) "Om" yang mistik dan magis mendorong umat manusia untuk membenamkan diri dan mencari jati diri di dalamnya. Nilai-nilai luhur yang terkandung dalam "Om" diyakini dapat memberikan pencerahan bagi umatnya. Hal tersebut telah dilakukan dan diwariskan oleh leluhur kita terdahulu sehingga kita mempunyai kewajiban moral dan spiritual ke depan untuk memelihara dan mengembangkan kepada generasi muda secara berkelanjutan.

Olah prana dengan memanfaatkan Pranawa Mantra "Om" merupakan salah satu praktek spiritual untuk membangkitkan dan menghidupkan rasa keagamaan yang bermoral. Pendakian spiritual yang tekun di bawah bimbingan guru spiritual sejati niscaya umat (bhakta) akan dapat memperoleh tahap pencerahan jiwa untuk bersatu dengan Brahman. Hal itu, pada gilirannya bermuara pada mencapaian tujuan kehidupan yang tenang, damai, dan bahagia lahir - batin. Sehubungan dengan hal tersebut, Pranawa Mantra "Om" berfungsi membangkitkan, menghidupkan, dan mempertebal rasa keagamaan yang mengarah pada praktek keagamaan dengan moral yang baik serta kesucian jiwa.

\section{Ritus Keagamaan}

Mantapnya rasa keagamaan, moral, dan spiritual umat akan berimbas positif pada ketaatan dan kedisiplinan umat dalam melaksanakan ritus keagamaan. Keramaian dan kesemarakan pelaksanaan upacara yadnya akan memberikan arti dan kepuasan tersendiri bagi penyelenggaranya, lebih-lebih hal itu dilakukan dengan kesucian hati dan serba satwika. Keadaan seperti itu menunjukkan kwalitas ideal ritus keagamaan. Dalam kaitan itu, Pranawa Mantra "Om" berfungsi sebagai instrumen kekhusukan dan kekudusan upacara yadnya dalam satu-kesatuan yang utuh.

Daya Mistik dan Magis

Apabila rasa dan ritus keagamaan sudah dilandasi dengan moral yang baik serta kesucian jiwa maka betapapun besar dan rumitnya hajatan, berkat Sabda Brahman "Om" diyakini dapat menghalau segala rintangan. Bayangkan, pada awal penciptaan dunia dengan segala isinya dapat ditafsirkan bahwa getaran suara "AUM" menimbulkan kekacauan yang mengarah pada terjadinya utpathi/srsthi, stithi, dan pralina/laya alam semesta beserta isinya. Demikianlah daya mistik bunyi (aksara) "Om" dipercaya dapat memberikan vibrasi kesucian, melindungi dan menyelamatkan umatnya dari berbagai kesulitan. Bahkan, jika umatnya berjapa, olah prana, membikin jimat, melakukan pengobatan, dan sebagainya dengan memanfaatkan bunyi (aksara) "Om" yang berdaya magis juga diyakini akan manjur. Sehubungan dengan hal tersebut, bunyi (aksara) "Om" berfungsi sebagai kekuatan yang tersembunyi yang dapat mengatasi berbagai rintangan yang dihadapi oleh umat manusia dan mengantarkannya kepada kesucian, kebenaran, kebaikan, dan kebahagiaan. 
Penginderaan Relatif

Pengetahuan dan pengalaman spiritual (termasuk di dalamnya rasa keagamaan) umat manusia berbeda satu sama lain. Perbedaan itu menyebabkan daya tangkap atau penginderaannya relatif terhadap Brahman. Kita mengetaui dan melihat kenyataan bahwa ada berbagai cara praktek keagamaan, moral, dan spiritual dengan berbagai tingkat dan tahapannya. Singkat kata, tetap saja terjadi perbedaan dalam penginderaan terhadap Tuhan. Ya, itu relatif bagi setiap orang. Pernyataan Anand Krishna (2008: 67) menarik dan pantas untuk direnungkan: "Jika kau mempercayainya, ... maka Aum itulah Brahman. Atau ALM, terserah, tergantung pada pendengaranmu. Pendengaranmu bagimu, pendengaranku bagiku.... Sesungguhnya Hyang Terdengar itu satu dan sama adanya". Sehubungan dengan hal tersebut, bunyi (aksara) "Om" berfungsi sebagai pusat penginderaan terhadap Brahman, yang proses dan hasil (budaya) keterhubungannya menjadi relatif bagi setiap orang.

Keseimbangan

Makna dan fungsi ini jelas masih berhubungan dengan uraian makna dan fungsi bunyi (aksara) "Om" terdahulu. Intinya, Tuhan ber-yadnya dalam penciptaan dunia dengan segala isinya melalui tiga kekuatan yang fungsional dalam manifestasinya sebagai Brahma, Wisnu, dan Siwa. Oleh karena itu, umat manusia sebagai salah satu ciptaannya yang dianugrahi sabda, bayu, dan idep wajib untuk melaksanakan yadnya sesuai dengan kemampuannya menurut desa, kala, dan patra. Hal itu penting dilakukan sebagai swadharma yang sifatnya timbal-balik agar terjadi keseimbangan, keselarasan, dan keharmonisan kesinambungan siklus penciptaan, pemeliharaan, dan peleburan dalam arti luas. Praktek kehidupan rasa keagamaan, moral, dan spiritual yang demikian tentunya akan dapat mengantarkan umat manusia pada tujuan yang diinginkan: tenang, damai, dan bahagia lahir - batin. Dalam kaitan itu, bunyi (aksara) "Om" berfungsi sebagai objek konsentrasi yang memberi sentuhan agar selalu ingat (eling), mempunyai kepekaan dan kesadaran ber-swadharma untuk ber-yadya; melakukan sadhana spiritual, dana punia, dan sebagainya.

\section{SIMPULAN}

\section{Simpulan}

Berdasarkan pembahasan masalah di depan dapat disimpulkan bahwa Pranawa Mantra "Om" dalam perspektif Linguistik Budaya memiliki bentuk, makna, dan fungsi, yang dijabarkan secara singkat berikut ini.

Pranawa Mantra "Om" adalah simbol Nada Brahman yang terdiri atas sebuah kata bersuku satu. Umat Hindu Bali menandai Pranawa Mantra "Om" dengan Om/Ong-kara dan diucapkan secara bervariasi dengan tulisan fonetis: \{öm, ön, wön, aüm, üm\}. Nada Brahman yang simbolik tersebut merupakan salah satu instrumen vital dan strategis untuk pemujaan (sembahyang), persembahan yadnya, meditasi, dan sebagainya. Oleh karena itu maka Pranawa Mantra "Om" menjadi pusat perhatian bagi orang-orang suci; para guru, bhakta, dan penekun spiritual dari sejak zaman Weda hingga dewasa ini. Pranawa Mantra "Om sangat dipercaya mengandung daya penyucian untuk ketenangan, kedamaian, dan pencerahan jiwa (spiritual). Demikian pula Pranawa Mantra "Om" memiliki daya magis dan mistik untuk keselamatan, kejayaan, dan kesuksesan dalam meraih cita-cita. Ketepatan dalam perapalannya sesuai dengan fungsinya dapat memberikan fibrasi daya-daya mantra/japa mantra dimaksud. Pranawa Mantra "Om" diidentifikasikan memiliki makna dan fungsi: (1) kemahaesaan dan 
kemanunggalan Tuhan, (2) siklus/daur kehidupan, (3) rasa keagamaan, moral, dan spiritual; (4) ritus, (5) daya mistik dan magis, (6) penginderaan relatif, dan (7) keseimbangan.

\section{Saran}

Studi pendahuluan yang singkat dan sederhana ini kiranya dapat menggelitik para peminat, pemerhati, dan peneliti untuk melalukan studi yang lebih luas dan mendalam pada masa-masa yang akan datang. Penulis merasa kecil sekali di hadapan Brahman ketika akan mencoba mulai mengungkapkan realitas bahasa dan budaya sehubungan dengan kemahaesaanNya yang simbolik itu. Namun begitu, berbekal pada keyakinan bahwa beliau pasti akan berkenan memberkati penulis untuk melakukan studi ini. Akhirnya penulis percaya diri untuk memulai dan terus menulis sehingga terwujudnya tulisan seperti sakarang ini. Pada kesempatan yang baik ini, tidak lupa penulis mengucapkan terima kasih kepada semua pihak terkasih yang tidak sempat disebutkan satu per satu yang telah memberikan dorongan dan dukungan kepada penulis. Semoga Brahman memberkati kita semua dapat menjadi insan yang bermakna, berguna, penuh kasih, dan berbahagia.

\section{DAFTAR PUSTAKA}

Anadas Rao, 2008. Pranawa Om. Surabaya: Paramita.

Anandakusuma, Sri Reshi. 1973. Aum, Kitab Suci Kusuma Dewa. Morodadi.

Anand Krishna. 2007. Panca Aksara, Membangkit Keagamaan dalam Diri Manusia. Denpasar: PT Offset BP.

Bagus, I Gusti Ngurah. 1980. Aksara dalam Kebudayaan Bali. Pidato Pengukuhan Guru Besar dalam IImu Antropologi Budaya pada Fakultas Sastra Universitas Udayana.

Bakker SJ., J.W.M. 1992. Filsafat Kebudayaan, Sebuah Pengantar. Jakarta: B.P.K. Gunung Mulia.

Bawa, I Wayan dan I Wayan Cika. 2004. Bahasa dalam Perspektif Kebudayaan. Universitas Udayana.

Bell, Roger T. 1976. Sociolinguistic: Goal, Aproaches and Problem. New York: St. Martin's Press.

Carrol, John B. (Ed.). 1979. Language, Thougt, and Reality (Selected Writtings of Benjamin Lee Whorf). Cambridge, Massachusetts: The M.I.T Press.

Chawdhri, L.R. 2003. Rahasia Yantra, Mantra \& Tantra. Surabaya: Paramita.

Darmayasa. 2007. Meditasi Angka. Denpasar: PT Percetakan Bali. 
Djendra, Wajan. 1975. "Fonologi Bahasa Bali". Dalam Masalah Pembakuan Bahasa Bali, oleh I Gusti Ngurah Bagus (Ed.). Singaraja: Balai Penelitian Bahasa, Departemen Pendidikan dan Kebudayaan.

Gara, I Wayan. 2006. 'Wacana Samodana Usaba Sambah pada Masyarakat Tenganan Pegringsingan: Sebuah Kajian Linguistik Kebudayaan". Disertasi untuk Memperoleh Gelar Doktor pada Program Doktor, Program Studi Linguistik, Program Pascasarjana Universitas Udayana.

Halliday, M.A.K. dan Ruqaiya Hasan.1989. Language, Cntext, and Text: Aspect of Language in Social Semiotic Perspective. Victoria: Deakin University Press.

Ibrahim, Abd. Syukur. 1995. Sosiolinguistik: Kajian, Tujuan, Pendekatan, dan Problem. Surabaya - Indonesia: Usaha Nasional.

Jendra, Wayan. 1980. Sebuah Ikhtisar Fobologi Bahasa Bali. Denpasar: Jurusan Sastra Jawa Kuna, Fakkultas Sastra, Universitas Udayana.

Koentjaraningrat. 1992. Kebudayaan Mentalitas dan Pembangunan. Jakarta: PT Gramedia Pustaka Utama.

Kuper, Adam dan Jessica Kuper (Ed.). 2000. Ensiklopedi Ilmu-ilmu Sosial. Terjemahan oleh Haris Munandar. Jakarta: PT Raya Grafindo Persada.

Miles, Mathew B. and A. Michael Huberman. 1992. Qualitative Data Analysis. Terjemahan oleh Tjetjep Rahendi Rohidi. Sage Publisher Publications, Inc.

Moleong, Lexy J. 2002. Metodologi Penelitian Kualitatif. Bandung: PT. Remaja Rosdakarya.

Muhadjir, Noeng. 1989. Metodologi Penelitian Kualitatif: Telaah Positivistik, Rasionalistik, dan Fenomenologistik. Yogyakarta: Rake Sarasin.

Nala, Ngurah. 2006. Aksara Bali dalam Usada. Surabaya: Paramita.

Palmer, Gary B.1996. Toward a Theory of Cultural Linguistics. Austin, USA: University of Texas Press. 